\title{
Stress and Arousal Rhythms in Cigarette Smokers, Deprived Smokers, and Non-Smokers
}

\author{
A. C. PARROTT* and C. JOYCE \\ Department of Psychology, University of East London, London E15 4LZ, UK
}

Feelings of stress and arousal were assessed in sedative smokers $(N=26)$, stimulant smokers $(N=14)$, nicotinedeprived smokers $(N=14)$, and non-smokers $(N=22)$. The self-rating questionnaire was completed every 2 hours, from waking until late evening. Feelings of anxiety/stress decreased over the day in non-smokers, and both groups of smokers, but increased in deprived smokers (group $\times$ time interactions: $p<0.001$ ). This demonstrates the anxiogenic effects of nicotine deprivation, and confirms that one major reason for smoking is to avoid the deleterious effects of nicotine deprivation. While average daily stress levels did not differ significantly between smokers and non-smokers, both groups of smokers started the day with higher stress than non-smokers, but ended the day with slightly lower stress (group $\times$ time interactions: $p<0.001$ ). Thus the gradual accumulation of nicotine does have anxiolytic effects. The arousal findings were complex, with different circadian patterns found across all four groups.

KEY wORDS-Smoking, nicotine, cigarette, stress, anxiety, arousal, mood, diurnal rhythm, circadian rhythm.

\section{INTRODUCTION}

Cigarette smoking and other forms of nicotine administration can affect many psychological functions. Smoking-deprivation often generates feelings of tension and irritability, while smoking generally leads to feelings of relaxation and pleasure (Heimstra, 1973; Schachter, 1978; Speilberger, 1986; Gilbert and Wesler; McNeil, 1991). With reference to arousal, when cigarette smokers are deprived of nicotine, they generally display EEG signs of reduced arousal, and impaired performance on sustained attention tasks (Knott and Venables, 1977; Wesnes and Warburton, 1983; Parrott and Roberts, 1991). In contrast, smoking often leads to EEG signs of increased alertness, and improved vigilance performance (Knott and Venables, 1977; Wesnes and Warburton, 1983; Warburton, 1988; Wesnes and Parrott, 1992). Whether smoking generates true improvements in alertness and mood state, or just reverses the deleterious effects of deprivation, has been widely debated (Surgeon General, 1988; Warburton, 1988; Parrott and Roberts, 1991; Wesnes and Parrott, 1992).

Cigarette smoking therefore influences both cognitive functions (information processing), and

*Author to whom correspondence should be addressed. emotional states (anxiety, pleasure). These psychological changes have been linked together in the 'Arousal Modulation' theory of smoking. This theory can be criticised on theoretical and empirical grounds, since few studies have simultaneously assessed the effects of cigarettes upon stress and arousal (Parrott, 1992). It was for this reason, the present series of studies were undertaken. Feeling states were assessed immediately prior to smoking, then immediately after each cigarette, over a whole day of smoking (O'Neill and Parrott, 1992; Parrott, in press, unpublished). One consistent finding to emerge was the diurnal rhythm for feelings of anxiety/stress. Stress levels commenced high in the morning, then reduced over the rest of the day. This monotonic function was quite different from the inverted-U function typical for arousal (Folkard, 1983; Thayer, 1989). It was therefore hypothesised that this decreasing stress may reflect the daily accumulation of nicotine, since: 'Smoking represents a multiple dosing situation with considerable nicotine accumulation' (Surgeon General, 1988, p38). In order to test this hypothesis, diurnal patterns of anxiety/stress in non-smokers and smokers need to be compared. This was the main aim of the present study. Further aims were to compare the circadian rhythms of arousal in smokers and non-smokers, and to assess all these mood state changes in deprived smokers. 


\section{METHOD}

\section{Subjects}

University staff and students comprised the unpaid volunteers. Of the 95 who agreed to participate, 76 returned fully-completed questionnaires. Smokers using less than 10 cigarettes per day, or with identical Smoking Motive Questionnaire (SMQ sedative/stimulant subscale scores (see below), were excluded from further analysis. The remaining smokers were divided into two subgroups (Parrott, in press):

Sedative smokers $(N=26: 15$ female, 11 male. Age range: $19-35$ years) comprised those with higher sedative than stimulant SMQ subscale scores.

Stimulant smokers ( $N=14: 5$ female, 9 male. Age range: $25-40$ years) comprised those with higher stimulant than sedative SMQ subscale scores.

The above smokers were also asked if they would abstain from smoking for one day; those who agreed comprised the third group.

Deprived smokers $(N=14: 8$ females, 6 males. Age range: 19-27). Eleven subjects came from the sedative subgroup, while 3 were from the stimulant subgroup.

Non-smokers ( $N=22$ : 12 female, 10 male. Age range: 19-55) comprised those who had never smoked, or had not smoked for over one year.

There were no significant differences in age or cigarette consumption between groups.

\section{Questionnaires}

The Smoking Motive Questionnaire (SMQ), (West and Russell, 1985; based upon Russell et al., 1974), was completed by all subjects. The sedative and stimulant scales were used for subgroup classification (see above).

The mood state questionnaire ( $O$ 'Neill and Parrott, 1992) comprised two bipolar stress questions, and two bipolar arousal questions. They were chosen for their high loadings on Mackay's (1978) stress and arousal factors. The questionnaire is summarised below:

$\begin{array}{lc}\text { TENSE- } & \begin{array}{c}\text { strongly, slightly, neither,... } \\ \text { slightly, strongly -RELAXED } \\ \text { strongly, slightly, neither,... } \\ \text { slightly, strongly -CALM }\end{array} \\ \text { NERVOUS- } & \begin{array}{c}\text { stightly, strongly neither, ... } \\ \text { strongly, slightly, neither,... } \\ \text { slightly, strongly -DROW }\end{array} \\ \text { ENERGETIC } & \text { ALERT- }\end{array}$

Each question was scored from 1 to 5 . The first two questions were combined to produce the overall stress score $(2=$ low, $10=h i g h)$; the two latter questions for the arousal score $(2=$ low, $10=$ high $)$. This set of scales was completed at the following times: 10 minutes after waking, 10am, 12noon, $2 \mathrm{pm}, 4 \mathrm{pm}, 6 \mathrm{pm}, 8 \mathrm{pm}$, and $10 \mathrm{pm}$; on day when subjects would not be consuming alcohol.

\section{Analysis}

The ANOVA model comprised two main factors: group (sedative/stimulant smokers), and time ( 8 periods over the day). An initial ANOVA was performed on the overall data from all four groups (using SPSS-pc). Then a series of ANOVAs between subgroup pairs was undertaken. The reason for this procedure was that conventional comparison tests (eg. Dunnet, Duncan) can be applied to main factors, and the crucial statistic here was the time $\times$ group interaction. This interaction term can be fully interpreted only when it is the product of a two-group comparison.

\section{RESULTS}

Group mean stress scores over time are shown in Figure 1. The ANOVA findings are presented in Table 1. Feelings of stress for the overall analysis were significantly affected by: time, subjects group, and time $\times$ group interaction (all $p<0.001$; Table 1). The sources of these significant effects can be identified from the two-group comparisons. In the non-smoker/sedative smoker comparison, time $(p<0.001)$ and group $\times$ time $(p<0.001)$, were each significant. Both groups reported moderate feelings of stress after waking, a slight increase to an earlymorning peak, then a steady reduction over the rest of the day. However, sedative smokers started the day with higher stress than non-smokers, but ended the day with lower stress, thus generating the significant group $X$ time interaction (Figure 1). The non-smoker/stimulant smoker comparison was similar in all respects, with a non-significant group effect, but significant time $(p<0.001)$, and 
Table 1. ANOVA stress findings (two-tailed probability values)

\begin{tabular}{lccccccccccc}
\hline & \multicolumn{3}{c}{ Group } & \multicolumn{3}{c}{ Time } & \multicolumn{3}{c}{ Group $\times$ Time } \\
\hline & F-value & df & sig & F-value & df & sig & F-value & df & sig \\
\hline All groups & 19.2 & $3 ; 72$ & 0.001 & 11.3 & $7 ; 504$ & 0.001 & 8.04 & $21 ; 504$ & 0.001 \\
Non-smokers/ & 0.72 & $1 ; 46$ & ns & 17.96 & $7 ; 322$ & 0.001 & 3.44 & $7 ; 322$ & 0.001 \\
$\quad$ Sedative smokers & 1.16 & $1 ; 34$ & ns & 11.49 & $7 ; 238$ & 0.011 & 11.49 & $7 ; 238$ & 0.001 \\
$\begin{array}{c}\text { Non-smokers/ } \\
\text { Stimulant smokers }\end{array}$ & 0.08 & $1 ; 38$ & ns & 29.02 & $7 ; 266$ & 0.001 & 0.55 & $7 ; 266$ & ns \\
$\begin{array}{c}\text { Sedative smokers/ } \\
\quad \text { Stimulant smokers }\end{array}$ & 54.49 & $1 ; 34$ & 0.001 & 1.36 & $7 ; 238$ & ns & 8.23 & $7 ; 238$ & 0.001 \\
$\begin{array}{c}\text { Non-smokers/ } \\
\text { Deprived smokers }\end{array}$ & 43.15 & $1 ; 38$ & 0.001 & 2.08 & $7 ; 266$ & 0.046 & 23.49 & $7 ; 266$ & 0.001 \\
$\begin{array}{c}\text { Sedative smokers/ } \\
\text { Deprived smokers }\end{array}$ & 47.28 & $1 ; 26$ & 0.001 & 1.65 & $7 ; 182$ & ns & 16.54 & $7 ; 182$ & 0.001 \\
$\begin{array}{c}\text { Stimulant smokers/ } \\
\text { Deprived smokers }\end{array}$ & & & & & & & & & & \\
\hline
\end{tabular}

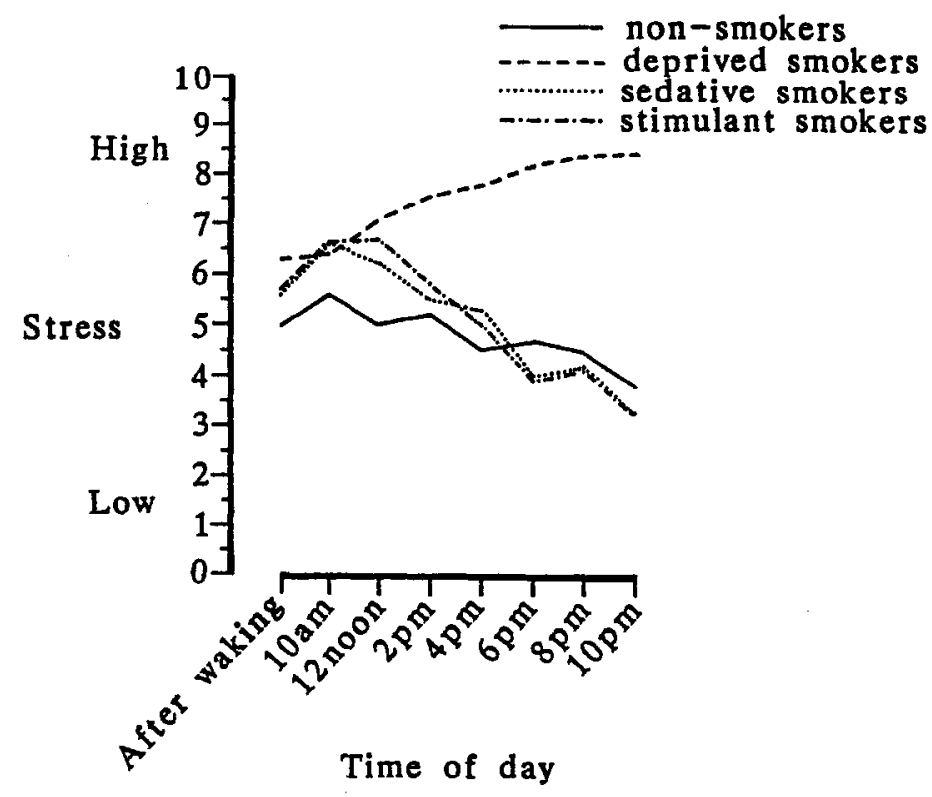

Figure 1. Stress ratings over the day

group $\times$ time interaction terms $(p<0.001$; Table 1). Thus stimulant smokers started the day with higher stress than non-smokers, but ended the day with slightly lower stress (Figure 1). In the sedative/ stimulant group comparison, neither of the ANOVA group terms approached significance, confirming that both types of smoker showed similar diurnal patterns of stress (Table 1; Figure 1). Results were very different with the deprived smokers. Stress levels on waking were similar to those of the other smokers, they then increased over the rest of the day (Figure 1). The group and group $x$ time interaction terms were highly significant, for all pair-wise comparisons ( $p<0.001$; Table 1).

Arousal scores over time are shown in Figure 2, while the ANOVA findings are summarised in Table 2. In the overall analysis, feelings of arousal were significantly affected by time $(p<0.001)$, and group $\times$ time interaction $(p<0.001$; Table 2$)$. The patterns of change over time differed between sub- 


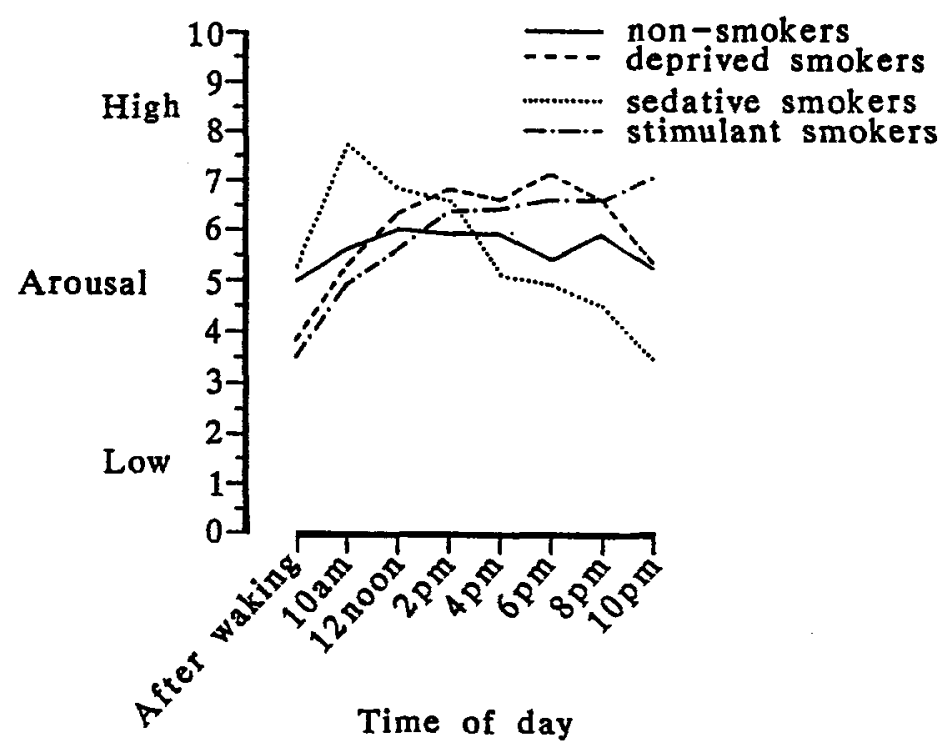

Figure 2. Arousal ratings over the day

Table 2. ANOVA arousal findings (two-tailed probability values)

\begin{tabular}{lcccccccccc}
\hline & \multicolumn{3}{c}{ Group } & \multicolumn{3}{c}{ Time } & \multicolumn{3}{c}{ Group $\times$ Time } \\
\hline & F-value & df & sig & F-value & df & sig & F-value & df & sig \\
\hline All groups & 0.71 & $3 ; 72$ & ns & 14.34 & $7 ; 504$ & 0.001 & 8.41 & $21 ; 504$ & 0.001 \\
Non-smokers/ & 0.01 & $1 ; 46$ & ns & 12.42 & $7 ; 322$ & 0.001 & 8.13 & $7 ; 322$ & 0.001 \\
$\quad$ Sedative smokers & 0.46 & $1 ; 34$ & ns & 8.00 & $7 ; 238$ & 0.001 & 3.25 & $7 ; 238$ & 0.003 \\
$\begin{array}{l}\text { Non-smokers/ } \\
\quad \text { Stimulant smokers }\end{array}$ & 2.28 & $1 ; 38$ & ns & 7.58 & $7 ; 266$ & 0.001 & 19.32 & $7 ; 266$ & 0.001 \\
$\begin{array}{c}\text { Sedative smokers/ } \\
\quad \text { Stimulant smokers }\end{array}$ & 0.81 & $1 ; 34$ & ns & 8.50 & $7 ; 238$ & 0.001 & 1.99 & 0.057 & \\
$\begin{array}{c}\text { Non-smokers/ } \\
\quad \text { Deprived smokers }\end{array}$ & 2.74 & $1 ; 38$ & ns & 13.89 & $7 ; 266$ & 0.001 & 12.75 & $7 ; 266$ & 0.001 \\
$\begin{array}{c}\text { Sedative smokers/ } \\
\quad \text { Deprived smokers }\end{array}$ & 0.20 & $1 ; 26$ & ns & 17.20 & $7 ; 182$ & 0.001 & 2.20 & $7 ; 182$ & 0.036 \\
$\begin{array}{c}\text { Stimulant smokers/ } \\
\text { Deprived smokers }\end{array}$ & & & & & & & & & & \\
\hline
\end{tabular}

groups. All started the day with low arousal, but generated arousal peaks at different times: nonsmokers around mid-day (noon-4pm); sedative smokers earlier in the day (10am-noon); deprived smokers and stimulant smokers later in the day (6pm-10pm; Figure 2).

\section{DISCUSSION}

The main stress findings can be summarised as follows. Deprived smokers reported a diurnal pattern of increasing stress, whereas smokers and nonsmokers noted decreasing feelings of stress over the day. Both groups of smokers started the day with higher levels of stress than non-smokers, but finished the day with slightly lower stress. The higher initial stress with smokers may due to overnight nicotine deprivation, while their steeper decrease in stress may reflect the accumulation of nicotine over the day. Lastly, individual subject data (from parallel studies) shows that smokers experience vacilating feelings of stress over the day: high prior to smoking, low after smoking, then high before 
the next cigarette is lit. These stress/smoking relationships are analysed in more detail below.

Self-rated feelings of arousal typically follow an inverted- $U$ function, with peak arousal in the middle part of the day (Figure 43 in: Folkard, 1983). Inverted-U arousal functions were generated previously (O'Neill and Parrott, 1992; Parrott, in press), but some variation was apparent here. Nonsmokers showed an arousal peak around mid-day, stimulant smokers and deprived smokers later in the day, while sedative smokers reported an earlier arousal peak (Figure 2). These findings suggest that stimulant smokers experienced increasing feelings of arousal, while sedative smokers demonstrated decreasing arousal over the day. If confirmed this would suggest that 'sedatives' were smoking to lower their arousal, while 'stimulants' were smoking to generate heightened alertness. However, it should be noted that these patterns were quite different from those found previously, when sedative and stimulant groups displayed very similar inverted-U functions (O'Neill and Parrott, 1992; Parrott, in press).

Deprived smokers reported increasing levels of stress over the day (Figure 1). In contrast, nonsmokers and smokers reported moderate stress on waking, a slight increase to an early morning peak, then decreasing feelings of anxiety/tension as the day progressed (each group $\times$ time interaction $p<0.001$; Table 1). These findings are in agreement with the literature on cigarette smoking and mood. Smoking deprivation generally leads to feelings of irritability, stress and tension (Heimstra, 1973; Hughes et al., 1984; West and Russell, 1985; Surgeon General, 1988). In contrast, smoking often leads to feelings of relaxation and pleasure (Frith, 1971; Heimstra, 1973; Schachter, 1978; Speilberger, 1986). Thus Wesnes et al. (1984, p233) have noted: 'The vast majority of smokers respond positively to the question "Smoking helps me to relax".' The neurochemical basis for these actions centres around the cholinergic system, although a range of explanatory models have been proposed (Surgeon General, 1988, p408-413; Gilbert and Wesler, 1989).

Smokers started the day with higher stress than non-smokers, but ended the day with slightly lower stress (Figure 1). Drug $\times$ time interactions were significant for the non-smoker/sedative group comparison, and the non-smoker/stimulant group comparison (both $p<0.001$; Table 1 ). This suggests that the accumulation of nicotine over the day has an anxiolytic effect, also that this anxiolytic effect is independent of smoking typology, as noted earlier (O'Neill and Parrott, 1992; Parrott, in press). The higher initial stress of smokers may reflect overnight nicotine deprivation, with smoking abstinence leading to impaired mood. Alternatively, it may comprise a return to 'normal' anxiety, with smokers having slightly higher average traitanxiety than non-smokers (Cherry and Kiernan, 1978; Warburton, 1988). Non-smokers demonstrated a pattern of decreasing stress over the day (Figure 1). Thayer (1989) has noted a similar diurnal rhythm: 'The tense-energy mood is usually present during the first third of the day', while later in the day: 'Tense-energy would gradually be replaced by tense-tiredness'. (Thayer, 1989, p53. Note: tenseenergy/tiredness is equivalent to Mackay's stress factor; see Thayer, 1989, p61).

Average daily stress levels for smokers and nonsmokers, did not differ significantly. Thus it might be concluded that smoking does not produce any mood advantage over non-smoking, whereas deprivation clearly impairs mood (Figure 1). This conclusion is similar to that offered by Schachter (1978). He demonstrated that non-smokers were similar to smokers in terms of degree of pain-stress they would tolerate, while deprived smokers tolerated significantly less pain-stress than the other two groups: 'It would appear then that smoking is not anxiety reducing but, rather, that no smoking or insufficient nicotine is for the heavy smoker, anxiety increasing' (p210). McNeil (1991) came to similar conclusions with child smokers: 'Feeling calmer when smoking was consistently related to reports of aversive withdrawal effects when attempting to give up. Rather than a direct effect of their smoking, feeling calmer may therefore come about as a relief of incipient withdrawal symptoms' (p591). The present findings clearly support this conclusion. They demonstrate that one major effect of smoking is to forestall the deleterious mood effects of cigarette withdrawal.

One controversy in the mood/smoking literature, is whether smoking 'improves' mood, or whether the apparent improvements simply reflect the reversal of drug deprivation. The Surgeon General (1988, p407) has stated: 'Caution must be exercised in generalising about smoking and nicotine's effects on stress and mood because most laboratories compare smokers smoking with smokers not smoking. Few studies include the important control group of nonsmokers not smoking to allow unequivocal determinations of whether smoking and nicotine are stress reducing, or whether abstinence and smoking depri- 


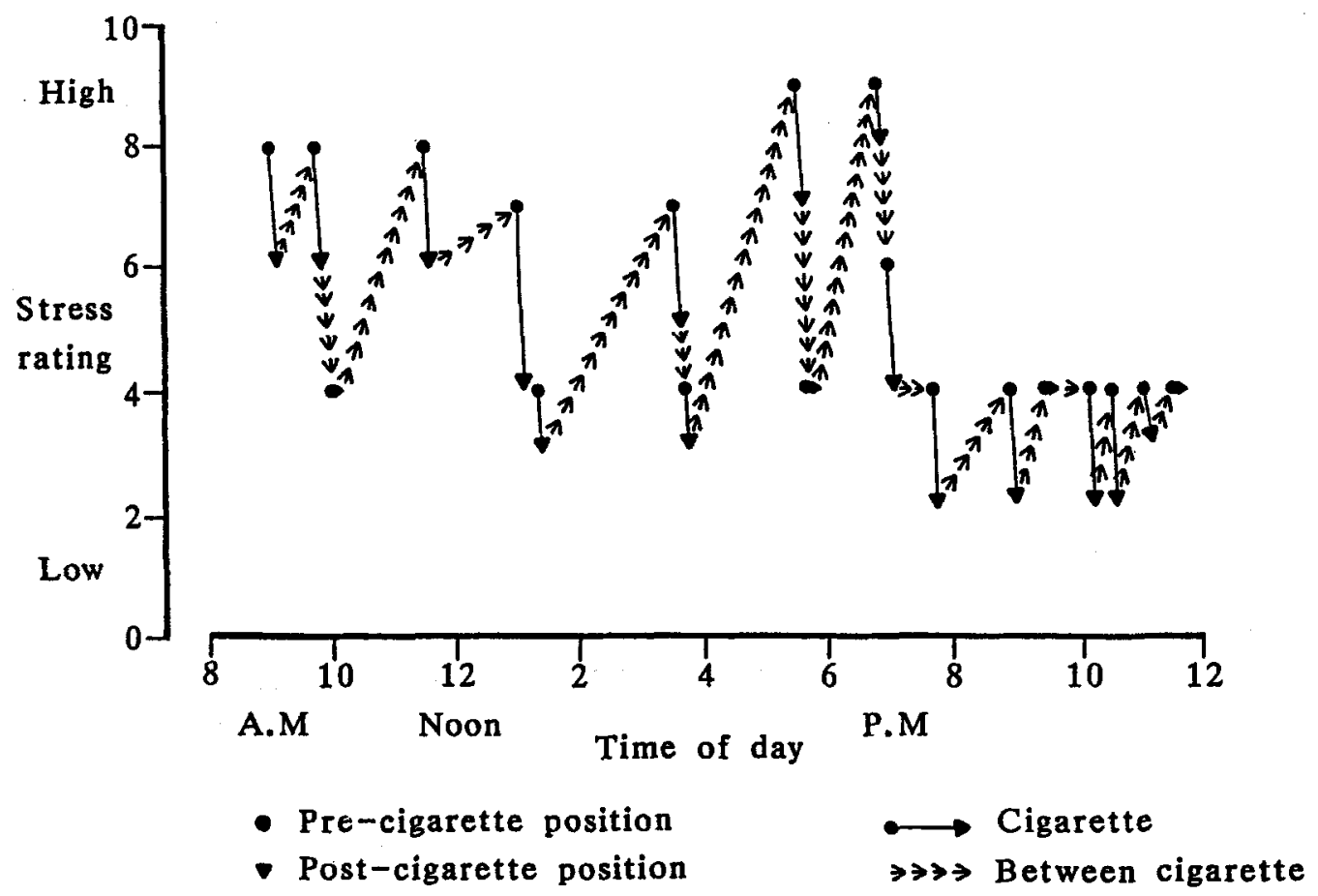

Figure 3. Feelings of stress before and after each cigarette, over a day of smoking: data from an individual (after: Parrott, unpublished)

vation are stress increasing: The present study provides this control group, but its findings support both explanations. Smoking clearly reverses the deleterious effects of nicotine deprivation (see above). However, anxiolytic effects are indicated by the significantly greater decrease in feelings of anxiety/stress over the day, for smokers compared to non-smokers. Although final stress levels late in the day were very similar for smokers and nonsmokers (Figure 1; Table 2). Thus the question of whether nicotine causes 'true' mood improvements, remains tantalisingly difficult to answer.

The total picture is however even more complex. In previous studies, it was demonstrated that many smokers experience vacilating feelings of stress over the day. Feelings were often high prior to each cigarette, low immediately after smoking, then high again prior to the next cigarette ( $O$ 'Neill and Parrott, 1992; Parrott, in press, unpublished). This pattern can be illustrated by one subject's data (Figure 3; from Parrott, unpublished). When cigarettes were smoked in quick succession, cumulative stress reduction often occurred, but when the inter-cigarette interval was prolonged ( +30 minutes), stress levels generally increased again (Figure 3). This subject therefore experienced alternating moods over the day, a pattern evident in many other individuals, and in the group data from all studies ( $\mathrm{O}^{\prime}$ Neill and Parrott, 1992; Parrott, in press, unpublished). Many smokers therefore experience repetitive fluctuations in feeling states, with each period of cigarette deprivation comprising an intermittent source of stress. In pharmacodynamic terms, there is an inherent logic behind these reciprocal mood changes, given the number of cigarettes smoked each day. If the 'beneficial' effects of smoking were longer lasting, then cigarettes would need to be consumed less frequently (compare with cannabis use). Furthermore, if smoking comprises a source of stress, then smokers should become less stressed when they quit the habit. This prediction was empirically confirmed in a recent nicotine-gum trial. Successful quitters reported significantly lower levels of stress 6 months after quitting, than at baseline. Stressful life events were also recorded, but were unchanged over this period, indicating a genuine reduction in propensity for stress (Parrott, Craig, and Phillips, submitted). 
These findings are also in agreement with West (1992), who suggested that 'anxiety reduction' was the process by which nicotine-gum helped smoking cessation.

These findings have a number of implications for the mood/smoking literature. Circadian factors are central to arousal research (Folkard, 1983), but are also important for stress. Thus a diurnal pattern of decreasing stress seems to be normal for both smokers and non-smokers (Figure 1). The present findings agree with the literature on mood and smoking: deprivation associated with negative moods, smoking with positive moods (Gilbert and Wesler, 1989). However, they demonstrate that the $\mathrm{mood} / \mathrm{smoking}$ relationship is far more complex than previously described. Many smokers experience rapid alternations in feeling states, closely related to their patterns of cigarette use (Figure 3). Smoking is therefore a direct cause of stress, because of acute nicotine withdrawal. Hence the familiar cry of smokers who 'need' a cigarette, when they have not smoked recently. Put simply, while cigarettes are anxiolytic, the periods between cigarettes are anxiogenic. Lastly, and perhaps most importantly, this cycle of repetitive feeling state reversals, provides a clear psychological rationale for the addictive nature of smoking.

\section{REFERENCES}

Cherry, N. and Kiernan, K. (1978). A longitudinal study of smoking and personality. In: Smoking Behaviour, Physiological and Psychological Influences, Thornton, R. E. (ed.) Churchill-Livingstone, Edinburgh.

Folkard, S. (1983). Diurnal variation. In: Stress and Fatigue in Human Performance. Hockey, R. (ed). Wiley, Chichester.

Frith, C. D. (1971). Smoking behaviour and its relation to the smokers immediate experience. British Journal of Social and Clinical Psychology, 10, 73-78.

Gilbert, D. G. and Wesler, R. (1989). Emotion, anxiety and smoking. In: Smoking and Human Behaviour. Ney, T. and Gale, A. (eds). Wiley, Chichester.

Heimstra, N. W. (1973). The effect of smoking on mood change. In: Smoking Behaviour: Motives and Incentives. Dunn, W. L. (ed). Winston, Washington DC.

Hughes, J. R., Hatsukami, D. K., Pickens, R. W., Krahn, D., Malin, S. and Lucknic, A. (1984). Effect of nicotine on the tobacco withdrawal syndrome. Psychopharmacology, 83, 82-87.

Knott, V. J. and Venables, P. H. (1977). EEG alpha correlates of nonsmokers, smoking smokers, and smoking deprivation. Psychophysiology, 14, 150-156.

McNeil, A. D. (1991). The development of dependence on smoking in children. British Journal of Addiction, 86, 589-592.

Mackay, C. J., Cox, T., Burrows, G. and Lazzerini, T. (1978). An inventory for the measurement of selfreported stress and arousal. British Journal of Social and Clinical Psychology, 17, 283-284.

Mangan, G. L. and Golding, J. F. (1984). The Psychopharmacology of Smoking. Cambridge UK, Cambridge University Press.

O'Neill, S. T. and Parrott, A. C. (1992). Stress and arousal in sedative and stimulant cigarette smokers. Psychopharmacology, 107, 442-446.

Parrott, A. C. (1992). Smoking and smoking cessation: effects upon human performance. Journal of SmokingRelated Disorders, 3, 43-53.

Parrott, A. C. (in press). Cigarette smoking: effects upon self-rated stress and arousal over the day. Addictive Behaviors.

Parrott, A. C. (unpublished). Stress and arousal in cigarette smokers: the role of individual difference factors.

Parrott, A. C. and Roberts, G. (1991). Smoking deprivation and cigarette reinstatement: effects upon sustained attention. Journal of Psychopharmacology, 5, 402-407.

Parrott, A. C., Craig, D. and Phillips, K. (unpublished). Nicotine chewing gum: patterns of use during successful smoking cessation. 7th Conference of the European Health Psychology Society (submitted).

Russell, M. A. H., Peto, J. and Patel, V. A. (1974). The classification of smoking by a factorial structure of motives. Journal of the Royal Statistical Society, 137, 313-346.

Schachter, S. (1978). Pharmacological and psychological determinants of smoking. In; Smoking Behaviour, Physiological and Psychological Influences. Thornton, R. E. (ed). Churchill-Livingstone, Edinburgh.

Speilberger, C. D. (1986). Psychological determinants of smoking behaviour. In: Smoking and Society: Towards a More Balanced Assessment. Tollison, R. D. (ed). DC Heath, Lexington.

Surgeon General (1988). Nicotine Addiction: the Health Consequences of Smoking. US Government Printing Office, Washington DC.

Thayer, R. E. (1989). The Biopsychology of Mood and Arousal. Oxford University Press, Oxford.

Warburton, D. M. (1988). The puzzle of nicotine use. In: The Psychopharmacology of Addiction. Lader, M. (ed). Oxford University Press.

Wesnes, K. and Parrott, A. C. (1992). Smoking, nicotine, and human performance. In: Factors Affecting Human Performance, Volume II. Smith, A. and Jones, D. (eds). Academic Press, London.

Wesnes, K. and Warburton, D. M. (1983). Smoking, nicotine and human performance. Pharmacology and Therapeutics, 21, 189-208.

Wesnes, K., Revell, A. and Warburton, D. M. (1984). Work and stress as motives for smoking. In: Smoking and the Lung. Cumming G, Bonsignore G (eds). Plenum. 
West, R. J. (1992). The nicotine replacement paradox West, R. J. and Russell, M. A. H. (1985). Pre-abstinence in smoking cessation: how does nicotine gum really work? British Journal of Addiction, 87, 165-167. smoke intake and smoking motivation as predictors of severity of smoking withdrawal symptoms. Psychopharmacology, 87, 334-336. 